\title{
ASPECTOS JURÍDICOS E POLÍTICOS DA TUTELA DO AMBIENTE COMO DIREITO FUNDAMENTAL À LUZ DO PENSAMENTO DE RONALD DWORKIN E JEREMY WALDRON
}

\author{
ENVIRONMENTAL LEGAL AND POLITICAL ASPECTS OF FUNDAMENTAL LAW \\ THROUGH THE THOUGHT OF RONALD DWORKIN AND JEREMY WALDRON
}

\section{Luiz Gustavo Gonçalves Ribeiro}

\begin{abstract}
Pós-doutor pela Universitá degli Studi di Messina/IT; Doutor, Mestre e Graduado em Direito pela Universidade Federal de Minas Gerais (UFMG); Professor da Graduação em Direito do Curso de Mestrado em Direito Ambiental e Desenvolvimento Sustentável da Escola Superior Dom Helder Câmara; Promotor de Justiça do Ministério Público do Estado de Minas Gerais. Email: lgribeirobh@gmail.com
\end{abstract}

Fernando Barotti dos Santos

Mestrando em Direito Ambiental e Desenvolvimento Sustentável pela Escola Superior Dom Helder Câmara; Graduado em Direito pela Escola Superior Dom Helder Câmara; Pesquisador do Grupo de pesquisa MAPE: Meio-Ambiente, Paisagem e Energia. Advogado. E-mail: fernando_barotti@hotmail.com

Recebido em: 21/12/2017

Aprovado em: 01/10/2018

RESUMO: O ensaio pretende trabalhar a proteção do Meio Ambiente, por meio das teorias de Ronald Dworkin e Jeremy Waldron, a partir da ótica constitucional do ambiente ecologicamente equilibrado. Trata-se, afinal, de direito fundamental, considerado precípuo para a manutenção da vida das presentes e futuras gerações, e de indivíduos fora das fronteiras jurisdicionais de um Estado. Dessa forma, o texto propõe avaliar o papel do judiciário e da política na preservação desse bem jurídico e como as teorias dos referidos filósofos podem se relacionar com ele. $\mathrm{O}$ presente trabalho foi desenvolvido sob o crivo da metodologia jurídico-teórica e raciocínio dedutivo, com pesquisa bibliográfica e documental. Conclui-se que tanto a Política como o Estado em sua função jurisdicional são aptos para promoverem a manutenção e a salvaguarda do meio ambiente.

Palavras-chave: Meio Ambiente; Política; Justiça; Ronald Dworkin; Jeremy Waldron.

ABSTRACT: The essay intends to work the protection of Environment, through the theories of Ronald Dworkin and Jeremy Waldron, from the constitutional point of view of ecologically balanced environment. It is, after all, a fundamental right which is considered to be essential for maintenance of the lives of present and future generations and of individuals outside the jurisdictional frontiers of a State. Thus, the text proposes to evaluate the role of the judiciary and politics in the preservation of this legal good and how the theories of the mentioned philosophers can relate to him. The present work was developed under the scrutiny of legal-theoretical 
methodology and deductive reasoning, with bibliographical and documentary research. It is concluded that both the Policy and the State in their jurisdictional function are apt to promote the maintenance and the safeguarding of environment.

Key- Words: Environment; Politics; Justice; Ronald Dworkin; Jeremy Waldron.

SUMÁRIO: Introdução; 1 Meio Ambiente: a Situação Histórica e Jurídica no Ordenamento Brasileiro; 2 Juízes E Dworkin: a Atividade Jurisdicional na Defesa e Implementação de Direitos Fundamentais; 3 Os Múltiplos Ruídos da Política: a Ótica Política de Jeremy Waldron na Proteção dos Direitos Fundamentais; Considerações Finais; Referências.

\section{INTRODUÇÃO}

A proposta do artigo é trabalhar uma construção da possibilidade do Meio Ambiente, enquanto direito fundamental difuso e coletivo, ser protegido pelo espaço político e jurídico brasileiro. Trata-se, então, da evolução da concepção do ambiente enquanto bem de consumo e enquanto direito, principalmente a partir da Constituição de 1988, bem como da análise do comportamento do judiciário e da política no tratamento desse bem jurídico.

Com a proposta de uma hipótese sobre a possibilidade de coexistência dos vieses político e jurídico permitirem proteção ao meio ambiente ecologicamente equilibrado, faz-se uma abordagem da perspectiva de Ronald Dworkin, no tocante ao viés jurisdicional, e sua teoria de direito como integridade. De outro lado, no aspecto político de tutela, o referencial teórico é Jeremy Waldron, que busca fundamentar a efetivação de direitos por meio do processo político e das leis, que são instrumento hábil para declarar os diretos sociais.

O presente ensaio foi elaborado sob o crivo da pesquisa bibliográfica, com raciocínio dedutivo e metodologia jurídico-teórica. $\mathrm{O}$ trabalho será distribuído em três tópicos principais: um primeiro, no qual será feita uma abordagem histórica do meio ambiente e de seu tratamento no ordenamento jurídico pátrio; no segundo, será observada a tese de Dworkin sobre a atividade jurisdicional e o papel interpretativo tendente à integridade do direito para fins da tutela dos direitos fundamentais, em especial, o meio ambiente. Por fim, no terceiro, será estudada a proposta de Waldron sobre a participação e a legitimidade política na defesa das garantias fundamentais, e a relação com o Meio Ambiente.

\section{MEIO AMBIENTE: A SITUAÇÃO HISTÓRICA E JURÍDICA NO ORDENAMENTO BRASILEIRO}

O meio ambiente no direito brasileiro inicialmente não era percebido como essencial à promoção da vida, tampouco os recursos eram considerados esgotáveis e finitos. Havia um hiato no que diz respeito à proteção ambiental, pois era dado a ele um tratamento secundário, de objeto, mormente diante do valor econômico e mercantilista atribuído à natureza. Nessa perspectiva, tudo que pudesse gerar capital era protegido para comércio futuro.

Assim, 
do descobrimento em 1500 até, aproximadamente, o início da segunda metade do século XX, pouca atenção foi dada ao Direito Ambiental no Brasil. Somente a título de curiosidade, pode-se citar que, por ocasião do descobrimento, vigoravam em Portugal as Ordenações Afonsinas, editadas sob o reinado de Dom Afonso IV, em 1393, nas quais já se encontravam algumas referências ao meio ambiente, mas acredita-se que não era uma preocupação, consciente, da proteção ambiental, e sim a preservação de sua utilidade para a Coroa Portuguesa [...] (COSTA, 2011, p. 46).

Houve no período colonial (entre os séculos XVI e XIX) e no republicano (entre 1889 e meados de 1960) ações pontuais do Poder Público, com a realização e manutenção da utilização dos bens naturais e a delimitação legislativa das atividades de exploração, de minério, fauna, flora, água e solo.

A Conferência de Estocolmo de 1972 foi um marco importante para a preservação do meio ambiente no Brasil e no mundo, uma vez que externou mais de vinte princípios, os quais foram adotados por algumas Constituições e servirão, certamente, para outras e futuras, como orientação. Com isso, países como o Brasil passaram a ser mais ativamente exigidos, afinal, era necessário, de fato e de direito, uma proteção ambiental mais rigorosa e integral.

A proteção mais eficaz dos espaços ambientais no Brasil ocorreu a partir da Lei de Política Nacional do Meio Ambiente (PNMA), de 1981. Em seu texto, introduziu-se a conceituação de Meio Ambiente no ordenamento jurídico brasileiro, que foi definido, no art. $3^{\circ}$, I, como "conjunto de condições, leis, influências e interações de ordem física, química e biológica, que permite, abriga e rege a vida em todas as suas formas (BRASIL, 1981)". A PNMA inseriu no direito brasileiro o espaço ambiental, natural ou não, como patrimônio público detentor de proteção em favor de indivíduos, grupos e coletividade.

A Constituição Federal de 1988 revela-se outro marco para o Meio Ambiente por tê-lo alçado à condição de bem constitucional, posto que inserido, com amplo espectro de proteção, no Capitulo VI, mais precisamente em seu art. $225, \mathrm{CF} / 88^{1}$. Com isso, ampliou-se a responsabilidade de preservação do meio ambiental, que passou a ser encartado com o status de direito fundamental, difuso e coletivo, compreendido este, segundo a melhor doutrina, como "valores ligados à dignidade da pessoa humana, é a limitação do poder. Eles são positivados no Direito interno, geralmente através de normas constitucionais". (MARMELSTEIN, 2008, p. 27).

No âmbito do Supremo Tribunal Federal (STF), visualiza-se a consolidação do meio ambiente como direito fundamental em decisões que abrigam a discussão sobre o tema. A título de exemplo, na ADI-MC 3540-DF, em reunião do Tribunal Pleno, o Ministro Celso de Mello, conhecido como o decano da Corte, aponta entendimento uníssono nesse sentido, a par de classificá-lo, no âmbito da terceira geração de direitos, como de natureza transindividual. Veja-se:

A PRESERVAÇÃO DA INTEGRIDADE DO MEIO AMBIENTE: EXPRESSÃO
CONSTITUCIONAL DE UM DIREITO FUNDAMENTAL QUE ASSISTE À
GENERALIDADE DAS PESSOAS.
- Todos têm direito ao meio ambiente ecologicamente equilibrado. Trata-se de um típico
direito de terceira geração (ou de novíssima dimensão), que assiste a todo o gênero
humano (RTJ 158/205-206). Incumbe ao Estado e à própria coletividade a especial
obrigação de defender e preservar, em benefício das presentes e das futuras geraçães,

\footnotetext{
${ }^{1}$ Art. 225. Todos têm direito ao meio ambiente ecologicamente equilibrado, bem de uso comum do povo e essencial à sadia qualidade de vida, impondo-se ao Poder Público e à coletividade o dever de defendê-lo e preservá- lo para as presentes e futuras gerações. (BRASIL, 1988, p. 131)
} 
esse direito de titularidade coletiva e de caráter transindividual (RTJ 164/158-161). (BRASIL, 2005, online, grifos nossos).

Importa ressaltar que o meio ambiente, por sua natureza e importância, não se limita a um local, espaço, a uma parte do país, mas, sim, diz respeito ao globo terrestre em sua integralidade. As palavras do Papa Francisco alertam para uma necessidade de um "pensar ecológico-social" como o retrato da proteção interconstitucional, almejada para todos os cidadãos do mundo:

\begin{abstract}
Quando falamos de 'meio ambiente', fazemos referência também a uma particular relação: a relação entre natureza e a sociedade que a habita. Isto impede-nos de considerar a natureza como algo separado de nós ou como uma mera moldura da nossa vida. Estamos incluídos nela, somos parte dela e compenetramo-nos. As razões pelas quais um lugar se contamina exigem uma análise do funcionamento da sociedade, de sua economia, de seu comportamento, de suas maneiras de entender a realidade. Dada a amplitude das mudanças, já não é possível encontrar uma resposta específica e independente para cada parte do problema. É fundamental buscar soluções integrais que considerem as interações dos sistemas naturais entre si e com os sistemas sociais. Não há duas crises separadas: uma ambiental e outra social; mas uma única e complexa crise socioambiental. As diretrizes para a solução requerem uma abordagem integral para combater a pobreza, devolver a dignidade aos excluídos e, simultaneamente, cuidar da natureza (FRANCISCO, 2015, p. 86).
\end{abstract}

Extrai-se, pois, do trecho acima, que o Meio Ambiente equilibrado, na concepção de Francisco (2015), é a casa comum dos cidadãos do mundo, não apenas de um local, de uma região ou de um país.

No caso brasileiro, a normatividade regente do Meio Ambiente, porquanto direito difuso e coletivo, pode ser extraída do Código de Defesa do Consumidor (CDC), mais precisamente no artigo 81, já que dotadas as normas ali legisladas de caráter geral, componente de um microssistema tutor de direitos de natureza transindividual, o que viabiliza o seu emprego à tutela do ambiente.

A guarda constitucional, bem como a preservação dos direitos fundamentais, coletivos e difusos, exige atuação preponderante de dois atores: Estado e Sociedade. Quanto ao primeiro, todas as suas funções principais - Legislativa Executiva e Judiciária -, devem promover formas de persecução da defesa ambiental adequada. Por força da Constituição, há uma obrigação estatal de proteger o espaço, não apenas como objeto jurídico-administrativo, mas sim como elemento essencial para sobrevivência, pois sem meio ambiente não há seres humanos, nem mesmo Estado. Quanto à sociedade, cumpre a tutela de sua própria casa, daquela que lhe oferecerá condições de existência, mínimas que sejam, porém vitais a cada ser habitante do planeta e, em consequência, da própria coexistência social.

Contudo, é na ação estatal que este ensaio se debruça, inobstante careça de maiores reflexões a atuação de cada um dos seres em prol do ambiente. Isso porque as políticas de Estado e de governo, sendo o ente estatal agente primeiro de manutenção e efetivação dos anseios sociais, encontram-se em frequente tensão, que motiva, ante as "circunstâncias diversas, associadas à Constituição, à realidade política e às competências dos Poderes [...]" (BARROSO, 2012, p. 23), o descumprimento de direitos ou a omissão de sua implementação.

A tensão diz respeito, em regra, aos poderes Executivo e Legislativo de um lado e, do outro, o Judiciário. Essa a razão de ser da implementação de políticas publicas pelo Poder Judiciário e dos tópicos seguintes, tendentes ao esclarecimento das questões políticas e jurídicas na implementação dos direitos fundamentais decorrentes dessa judicialização. Por tal razão, será estudado, a seguir, o referencial teórico de Ronald Dworkin na perspectiva da tutela jurisdicional dos direitos 
fundamentais, e de Jeremy Waldron, quanto à atividade política em prol da implementação dos referidos direitos, em especial, do meio ambiente.

\section{JUÍZES E DWORKIN: A ATIVIDADE JURISDICIONAL NA DEFESA E IMPLEMENTAÇÃO DE DIREITOS FUNDAMENTAIS}

Judicializar as questões da vida é um paradigma hoje visto e praticado na e pela sociedade, afinal esta conduz aos tribunais diversas expectativas de afirmação dos direitos. Isso significa que questões de extensa projeção política ou social são decididas por juízes e não por instâncias da política, ou seja, o Executivo e o Legislativo não têm dado uma resposta condizente aos anseios sociais, ou se omitem em tomar alguma decisão.

O fenômeno da judicialização "[...] envolve uma transferência de poder para juízes e tribunais, com alterações significativas na linguagem, na argumentação e no modo de participação da sociedade" (BARROSO, 2012, p. 2). Questões que possuem alta carga valorativa e moral, como demonstra Barroso, passam a ser discutidas por um órgão não político, mas de origem técnica:

Judicialização significa que questões relevantes do ponto de vista político, social ou moral estão sendo decididas, em caráter final, pelo Poder Judiciário. Trata-se, como intuitivo, de uma transferência de poder para as instituições judiciais, em detrimento das instâncias políticas tradicionais, que são o Legislativo e o Executivo. (BARROSO, 2012 p. 6)

A intensa atividade jurisdicional em questões de direitos fundamentais decorre de diversos fatores. Para Barroso (2012), são causas sociais, algumas delas de tendências mundiais e outras diretamente ligadas ao modelo das instituições do Brasil.

A redemocratização do país é fator essencial para a judicialização. Isso porque a Constituição de 1988 recuperou as garantias dos magistrados e o ambiente democrático "reavivou a cidadania, dando maior nível de informação e de consciência de direitos a amplos segmentos da população, que passaram a buscar a proteção de seus interesses perante juízes e tribunais" (BARROSO, 2012, p. 2). O Ministério Público, assim como a Defensoria Publica tiveram, pós 1988, o aumento da atuação na efetivação da democracia. O primeiro por uma atuação não mais restrita à área penal, mas também de fiscal da lei e da sua aplicação (BARROSO, 2012). Em relação à segunda, por tomar uma postura proativa de defesa dos hipossuficientes.

Outro fator de contribuição à expressiva atividade jurisdicional é a constitucionalização. De tão abrangente que é, a Carta aborda hoje inúmeras matérias anteriormente tratadas unicamente no âmbito do processo político, agora jurisdicionalizado pela Constituição, o que é tendência mundial observada em países como Portugal (Constituição de 1976), Espanha (Constituição de 1978) e Itália (Constituição de 1947). Com relação à Alemanha,

a principal referência no desenvolvimento do novo direito constitucional é a Lei Fundamental de Bonn (Constituição alemã), de 1949, e, especialmente, a criação do Tribunal Constitucional Federal, instalado em 1951. A partir daí teve início uma fecunda produção teórica e jurisprudencial, responsável pela ascensão científica do direito constitucional no âmbito dos países de tradição romano-germânica (BARROSO, 2005, p. 3)

No caso brasileiro, a Constituição Republicana de 1988 alcançou, como dito, temas que antes não pertenciam à esfera constitucional, o que apresentou reflexos na forma como as garantias 
sociais e individuais são hoje fiscalizadas. $\mathrm{O}$ controle de constitucionalidade brasileiro, instrumento de garantia de observância da Constituição, um dos mais amplos e complexos do mundo (BARROSO, 2012), foi elaborado sob o paradigma dos sistemas americano e europeu. Do sistema americano herdamos o controle de constitucionalidade difuso, já que juízes em todos os graus de jurisdição (magistrados em primeira instância, tribunais, tribunais superiores) possuem legitimidade para declarar a inconstitucionalidade de atos ou leis em desacordo com a Carta Política, afastando a aplicabilidade do dispositivo no caso concreto. Do modelo europeu buscouse o controle abstrato das normas: por meio de ação direta aceita-se que algumas matérias sejam levadas diretamente ao conhecimento da Corte Constitucional por rol de legitimados à propositura da ação (BARROSO, 2012).

Outra causa a ser destacada no tocante à judicialização é a falta de representatividade como reflexo do desacordo, ideológico e circunstancial, observado entre políticos e o povo. Matérias de grande repercussão, projetos de políticas públicas e da efetivação de direitos fundamentais ora passam invisíveis aos olhos do povo, ora são engavetados ou não discutidos em tempo hábil, extrapolando o momento ideal do debate.

Dito isso, o primado constitucional que dá lastro à judicialização emerge do princípio da inafastabilidade do controle jurisdicional previsto no art. $5^{\circ}, \mathrm{XXXV}, \mathrm{CF} / 88$ : "a lei não excluirá da apreciação do Poder Judiciário lesão ou ameaça a direito" (BRASIL, 1988, p. 15). Assim, ao cidadão é conferido o direito de peticionar e encontrar nos tribunais solução para suas insatisfações e problemas:

[...] O princípio da inafastabilidade da jurisdição deve ser visto, ao mesmo tempo, como a porta de entrada e a de saída da própria jurisdição. Isso porque não basta existir um mecanismo adequado para a solução das controvérsias, se as pessoas não tiverem acesso a ele; e, de igual forma, tampouco resolve assegurar contraditório, ampla defesa, isonomia, duplo grau de jurisdição, publicidade, etc., se o processo não tiver tutelas efetivas a ponto de proteger, tempestiva e eficazmente, o jurisdicionado de qualquer ameaça ou lesão já consumada aos seus direitos [...] O Estado, ao proibir a autotutela e assumir o monopólio da jurisdição, assumiu também o dever de tutelar de forma efetiva todos os direitos. Assim, na medida em que se impõe à jurisdição a necessidade de assegurar à parte a espécie de tutela mais adequada à efetiva e real proteção do direito invocado, fica mais evidente a conexão entre processo e direito material (RIBEIRO, 2008, p. 58).

Assim, "embora não tenham o batismo da vontade popular, magistrados e tribunais desempenham, inegavelmente, um poder político, inclusive o de invalidar atos dos outros dois Poderes" (BARROSO, 2012, p. 10).

E é a partir desse fato é que se passa à análise da teoria Dworkiana, a mesma que propõe que eles, juízes, conquanto não dotados de legitimidade política, sejam representantes legítimos da justiça e atores de sua efetivação na atividade de interpretação legislativa e de formação da integridade do direito.

A tese proposta por Dworkin (2010) atrela-se à melhor interpretação do direito em sintonia com a equidade, justiça e devido processo legal, em prol de uma melhor adequação e justificação das práticas jurídicas como um todo. Uma interpretação capaz de trazer ao caso concreto a resposta correta e ao direito a totalidade e a integralidade da justiça.

No contexto da tese dworkiana, esse jurista de capacidade e sabedoria sobre-humanas (DWORKIN, 2010), por ele intitulado Hércules, serviria de referência para aqueles que estão em condições de julgar, mas não possuem o preparo desse juiz. A Hércules cabe o dever de 
[...] construir um esquema de princípios abstratos e concretos que forneça uma justificação coerente a todos os precedentes do direito costumeiro e, na medida em que estes devem ser justificados por princípios, também um esquema que justifique as disposições constitucionais e legislativas (DWORKIN, 2010, p. 182).

O paradigma do juiz idealizado, Hércules, consistiria, na verdade, na melhor das interpretações de molde a tutelar direitos fundamentais. Não que se defenda que as soluções sejam únicas, mas que, no caso concreto, a hermenêutica esteja em sintonia com a equidade, à maior e melhor tutela do direito, em especial, no contexto ora discutido, ao meio ambiente. Afinal, os juízes têm como compromisso constitucional a promoção das liberdades e dos direitos fundamentais. Por mais que exista uma tomada política de decisões que promovam os direitos fundamentais, Dworkin (2010) relata que elas, muitas vezes, estão ligadas a posicionamentos majoritários, o que faz com que os julgadores, no exercício da atividade jurisdicional, protejam as minorias.

À luz de Dworkin, a interpretação jurisdicional tem por escopo a integridade do direito, uma perspectiva de salvaguarda da ordem pública, que mantém em harmonia a justiça, a equidade e o devido processo legal. O primado da integridade restringe a atuação do Estado, enquanto juiz, de forma a combater decisões que tratam a comunidade como mercadoria ou violem princípios endossados pelo Poder Público. Assim,

[...] o Direito como Integridade, além de uma interpretação específica da prática jurídica, funciona também, ele mesmo, como um programa interpretativo. O Direito como integridade não é apenas um fruto da interpretação, mas é também uma fonte de inspiração da interpretação mesma; pede a seus juízes que continuem, em sua prática, a interpretar o material que ele mesmo afirma ter interpretado com sucesso e se apresenta como a continuidade e como a origem das interpretações mais detalhadas que recomenda (MACHADO, 2016, p. 248)

A efetivação do direito, como integridade, insurge nas decisões judiciais. O magistrado lança mão de argumentos de princípios, postulados diferentes aos argumentos de política. Machado (2016, p. 248) conclui que a distinção é "[...] fundamental para diferenciar o trabalho dos juízes dos políticos parlamentares ou chefes do Executivo".

Os dois tipos de argumentos apresentados pelo jusfilósofo são essenciais para a integridade do direito, mas possuem delimitações e funções diferentes. Os argumentos de política para Dworkin se referem

[...] àquele tipo de padrão que estabelece um objetivo a ser alcançado, em geral uma melhoria em algum aspecto econômico, político ou social da comunidade (ainda que certos objetivos sejam negativos pelo fato de estipularem que algum estado atual deve ser protegido contra mudanças adversas) (DWORKIN, 2010, p. 36).

De outro lado, os argumentos de princípios detêm a finalidade de impedir a multiplicidade de respostas, fechando a interpretação dos juízes ao aplicarem o direito, impedindo arbitrariedades de respostas ao jurisdicionado. Igualmente, abrem espaço para interpretação moral do direito e da Constituição. O princípio, outrossim, é "[...] um padrão que deve ser observado, não porque vá promover ou assegurar uma situação econômica, política ou social considerada desejável, mas porque é uma exigência de justiça ou equidade ou alguma outra dimensão da moralidade." (DWORKIN, 2010, p. 36).

Dworkin concebe a defesa das garantias fundamentais e, portanto, também do Meio Ambiente, como papel nuclear do estado-juiz. Para o autor, os tribunais desempenham melhor o 
papel de recepção dos anseios sociais e respondem corretamente aos jurisdicionados. $\mathrm{O}$ estabelecimento do princípio da inafastabilidade de controle judicial, no Brasil, atribui às cortes legitimidade na revisão judicial dos atos do Poder Público, quando contrários à Constituição.

Retornando ao objeto cerne do diálogo, o Meio Ambiente ecologicamente equilibrado, na proposta dworkiana de salvaguarda, enquanto direito fundamental, deve ser assegurado pelo Judiciário, pois ele apresenta instrumentos e condições mais eficazes para a promoção dos direitos.

Há casos em que as decisões representam um evidente descompasso entre o que se tem por interesse político e a proteção jurisdicional. A titulo de exemplo, o Código Florestal (Lei 12.651/2012), que modificou a legislação anterior, teve sua constitucionalidade posta em dúvida por aparente violação constitucional material, em sede de Ação Declaratória de Inconstitucionalidade. O julgamento, ainda não concluído na data do artigo, teve início em setembro de 2017.

Outro caso em que o posicionamento político não se alinhou às propostas sociais é a vaquejada, um movimento cultural desportivo que objetiva a derrubada do boi para a vitória do vaqueiro. Tal atividade teve regulamentação estadual, entretanto, estudos técnicos, laudos e manifestações de organizações de defesa dos animais, lastrearam, por manifestação da Procuradoria-Geral da Republica (PGR), o argumento de que a prática cultural violava a proteção dos animais, a proteção do ambiente e a própria Constituição.

As leis estaduais foram questionadas por ação direta (ADI no 4983) no início de julho de 2013. Em 2016, houve decisão do STF declarando a inconstitucionalidade das leis dos Estados. Contudo, representantes do desporto, insatisfeitos com a decisão, procuraram, no espaço político, a solução, haja vista a aprovação de Emenda Constitucional (EC), que acrescentou um parágrafo ao art. 225 de forma a consolidar a prática como cultural. Esta EC, por sua vez, foi questionada perante o Supremo Tribunal Federal via ADI, proposta pela Procuradoria-Geral da República em defesa do interesse dos animais.

No âmbito político, com os exemplos citados acima, em matéria ambiental, o Congresso tem feito ecoar o espaço dos ruídos majoritários em prol da economia, da geração de emprego, esquecendo-se do Meio Ambiente, da discussão democrática e da abertura à opinião social. Dessa forma, em Dworkin, a solução para a preservação desse direito difuso e coletivo estará na guarda constitucional exercida pelo Judiciário, que deve garantir também, ainda que minoritário seja, o som dos excluídos.

A teoria dworkiana, ao avaliar a atividade jurisdicional do juiz na interpretação de leis e dos princípios, promove a integridade do direito, no sentido da defesa da Constituição e de molde a proporcionar a efetividade e harmonia dos direitos, dentre os quais, o do meio ambiente ecologicamente equilibrado.

Exposta a legitimidade da tutela ambiental pela teoria de Dworkin, será examinado, em seguida, o aspecto político da preservação do ambiente, o que se fará sob a ótica de Waldron.

\section{OS MÚlTiPlos RUÍdOS DA POLÍTICA: A ÓTICA POLÍTICA DE JEREMY WALDRON NA PROTEÇÃO DOS DIREITOS FUNDAMENTAIS}

Jeremy Waldron é jurista neozelandês, professor da universidade de Columbia, leitor de autores como Maquiavel, John Locke, Dworkin e H. L. A. Hart. É considerado um "pós-hartiano" tendo se filiado à tese positivista de Hart. Apresenta, todavia, uma nova roupagem ao positivismo jurídico, uma nova fundamentação ao direito positivo frente aos pós-positivistas e à teoria dworkiana. 
Waldron é descrito como positivista normativo, uma vertente que visualiza o positivismo não como simplesmente uma descrição de como o direito é, mas por oferecer uma contribuição a respeito do que o direito deve ser em uma sociedade democrática. É "uma teoria normativa que visa determinar o que o direito deve ser, não a respeito ao seu conteúdo, mas com respeito à sua forma"2 (CAMPBELL, 2004, p. 21, tradução nossa). O jurista busca uma teoria da autoridade, estabelecida para a democracia e a justiça.

A proposta de Waldron para a efetividade dos direitos fundamentais parte da atividade política, uma vez que os legitimados para discutirem as questões relevantes da sociedade devem se concentrar nos legisladores, aqueles eleitos pela sociedade. O autor não propõe uma confiança absoluta nos políticos, todavia, tece críticas a posicionamentos que enxergam o judiciário como caminho único para efetivação de direitos sociais.

No entendimento de Waldron (2003), os juízes são capazes de macular a ideologia da lei a cada dia, sob o manto da técnica jurídica, expressando suas intenções pessoais, até mesmo com a modificação de enunciados legais, com interpretações diversas de uma só lei. Ao julgar aplicando a lei, indicam que o significado da lei é o que eles apresentam no momento. Waldron aponta, todavia, o lado positivo de que o magistrado tem

[...] pelo menos, a gentileza de fingir que está descobrindo o que a lei era o tempo todo: ele não se apresenta explicitamente como um legislador. Na verdade, como todos nós sabemos, a lei é mudada todos os dias nos nossos tribunais de recursos, mas, na maioria das vezes, é mudada sob o disfarce de uma decorosa simulação, de que nada podia estar mais distante da nossa mente, ou da mente do tribunal, que uma aspiração legislativa. A linguagem e o estilo são declarativos mesmo se o conteúdo for revisionista. (WALDRON, 2003, p. 13-14, grifo no original).

Por outro lado, no âmbito político, a mudança da lei ocorre de forma aberta, escancarada e pública para a sociedade, o que para o autor apresenta-se como algo adequado, dado à legitimidade atribuída ao político pelo povo. Com essa legitimidade, o político pode promover modificações nos textos legais de molde a adequá-los à ordem constitucional e social. Dessa maneira os legisladores

[...] por contraste, têm a imprudência de dizer: 'Esqueçam o que o que a lei foi o tempo todo. É assim que ela vai ser agora.' E supõem-se que a lei foi mudada - mudada, como digo, descaradamente - em virtude do reconhecimento pela comunidade da intenção deliberada do corpo legislador de fazer exatamente isso. (WALDRON, 2003, p. 14, grifo no original)

Nessa premissa, Waldron tenta deslocar em sua filosofia jurídica a concepção predominante de interpretação do direito pelo judiciário, em vista da defesa do processo legislativo. O espaço de discussão dos valores morais, da justiça e diferentes ideias políticas, deve, por excelência, ser o espaço político e da política representativa. Afinal, para que a "[...] política e a legislação tenham dignidade, é preciso cuidar da própria cultura política e jurídica. E isso, em seu entendimento, não é uma tarefa apenas da filosofia política, mas é uma exigência que se faz também para a filosofia do direito [...]" (CONSANI, 2015, p. 2429), na busca da efetiva proteção dos direitos.

A retomada do papel político nas deliberações sobre direitos na tese waldroniana é fundamentada em Maquiavel. Parte-se da avaliação de que o tamanho da legislatura, o número de

\footnotetext{
2 "a normative theory that seeks to determine what the law should be, not with respect to its content, but with respect to its form"(CAMPBELL, 2004, p. 21).
} 
pessoas que a legislação deliberativa entrega, não pode causar descrença, nem desconfiança aos cidadãos que os elegeram. A pluralidade, o "tumulto" promovido em debates políticos, deve ser vista com bons olhos, pois é fruto da democracia, já prevista por Maquiavel, aquele que

[...] nos preveniu, quase quinhentos anos atrás, que não nos deixássemos lograr e pensar que a calma e a solenidade são marca de uma boa política, e que o barulho e o conflito são sintomas de patologia política. "Boas leis", disse ele, podem surgir "desses tumultos que muitos maldizem inconsideradamente" [..] "consideram mais os ruídos e os gritos que surgem em tais tumultos do que os bons efeitos que engendraram" (WALDRON apud MAQUIAVEL, 2003, p. 41).

As leis ditadas pelos representantes do povo são o resultado do enfrentamento político, de discussões que levaram em conta garantias e direitos inseridos na Carta Política; são, portanto, legítimas para serem aplicadas e produzir efeitos. Como apresentado pelo jusfilósofo, as legislações representam o fruto "[...] de assembleias amplas e polifônicas, e esta característica deveria ser crucial para nossa compreensão de como operar com as leis, isto é, de como interpretá-las e de como integrá-las no esquema mais amplo do direito"3 (WALDRON, 1999, p. 10).

Com tais ideias, são oponíveis ao autor duas questões básicas, as quais ele busca responder: Se o Parlamento é o local de desacordo político, promovido por seus diversos integrantes, que oscilam no comando da função, como assegurar que a autoridade não seja arbitrária? Qual a segurança dos cidadãos, para a manutenção da democracia, e dos direitos fundamentais dentro da proposta positivista normativa?

Waldron responde conhecendo a perspectiva de Dworkin, que considera o poder político arbitrário e carente de contenção pelo estado-juiz. Ele propõe uma resposta não ingênua para promoção da justiça e manutenção democrática, pois percebe a dicotomia política, reconhecendo inicialmente que "é na legislatura que nossos representantes discutem sobre a justiça; é na legislatura que discordamos sobre a justiça, onde temos segundos pensamentos sobre a justiça, onde revemos o nosso senso de justiça ou nos atualizamos" (WALDRON, 2003, p. 109).

$\mathrm{O}$ autor estabelece sua teoria democrática compreendendo as circunstâncias da política $a^{4}$, nas quais se verificam desacordos que, no entanto, são superados pelo parlamento em prol da harmonia. Desacordos existem nas sociedades, e sua existência não pode ser entendida, na concepção waldroniana, como sinal de crise, pois é compatível com a política.

Mesmo havendo discordância, esta é mínima no espaço legislativo haja vista a existência de um produto final de consenso. Contudo,

como, então, podemos esperar que a legislação seja levada a sério quando é determinada dessa maneira aparentemente arbitrária? [...] mesmo após a deliberação, as pessoas continuarão a discordar de boa fé sobre o bem comum e sobre questões de política, de princípios, de justiça e de direitos sobre as quais se espera que um Congresso delibere"5 (WALDRON, 1999, p. 89, tradução nossa).

\footnotetext{
3 "[...] the product of large and polyphonous assemblies. And this feature should be made key to our understanding of how to deal with them - how to interpret them and how to integrate them into the broader body of the law." (WALDRON, 1999, p. 10)

4 "[...] conceito adaptado daquele de 'circunstâncias da justiça' de John Rawls, segundo o qual em condições normais sob as quais a cooperação humana é possível e necessária, as regras sociais e legais criam certos direitos para estabilizar as relações humanas" (CONSANI, 2015, p. 2431).

5 "[...] How, then, can we be expected to take legislation seriously when it is determined in this apparently arbitrary way? [...] even after deliberation, people will continue to disagree in good faith about the common good, and about
} 
Waldron busca com sua pergunta apresentar para sociedade a legislação como a fonte do direito de forma superior, não fundamentada em arbitrariedades. $\mathrm{O}$ direito para o autor não deve estar pautado por uma verdade moral, mas tem por escopo preocupar-se com a eliminação de arbitrariedades, na salvaguarda das diversas razões morais coexistentes. Afirma, ainda, que pelo fato da Terra não ser habitada por um único individuo, mas sim por vários, todos buscam o mesmo bem comum (WALDRON, 1999). Logo, decidiram em prol desse bem comum, desvelando argumentos de equidade e razoabilidade para a autoridade da legislação. Dessa forma:

A decisão majoritária pode ser considerada equitativa em razão de conferir igual peso ao ponto de vista de cada pessoa envolvida no processo de decisão (ou pelo menos, igual peso ao voto de cada representante). Nesse sentido, assume-se que uma determinada questão sob deliberação é controversa, mas assume-se também que as opiniões em desacordo são razoáveis e que o resultado da votação, portanto, é merecedor de respeito porque foi alcançado segundo procedimentos equitativos e que levaram em consideração os pontos de vista divergentes [...] A decisão majoritária também é razoável exatamente em razão das circunstâncias da política (CONSANI. 2015, p. 2436)

A autoridade do direito deve encontrar capacidade de congregar e respeitar os desacordos, na observância a procedimentos. Partindo desse raciocínio, Waldron (1999) vislumbra o produto final da lei como pertencente ao Congresso, e não ao partido majoritário; a lei é do povo enquanto elaborada pelos seus representantes, para seu o povo e de todo ele e não apenas às maiorias ou minorias.

A legitimidade legislativa proposta por Waldron diminui, pois, o papel do judiciário no tocante à instrumentalização e tutela dos direitos fundamentais, ou seja, não há necessidade de a sociedade buscar constantemente o judiciário para dar soluções. Os magistrados, porquanto existentes produções legislativas, devem ser provocados à resolução de casos pontuais, que não envolvam conflitos de produção legislativa.

Isso porque, como dito, as matérias legislativas permanecem em debate e têm a solução no espaço originário que, na tese de Waldron, é o Legislativo. Nesse ambiente, o espaço deliberativo suprime os desacordos e promove leis condizentes aos anseios sociais.

Como exemplo dessa representação eficaz, na ótica waldroniana, pode-se destacar a legislação do ICMS - Ecológico, que busca uma maior ampliação das áreas verdes nos municípios, em troca de benefícios fiscais. A matéria é objeto de inúmeras discussões e encontra-se em implementação em diversos Estados do país, tendo em vista a competência constitucional do tributo.

Outro exemplo que também ilustra a tutela ambiental sob a ótica waldroniana, é a Lei n ${ }^{\circ} 9.985 / 00$, que dispõe sobre a gestão sustentável de florestas públicas, institui o Serviço Florestal Brasileiro, amplia a proteção florestal, dos biomas, do solo, das águas e demais recursos existentes nessas florestas.

Ambas as propostas foram antecedidas por acalorados debates em sede legislativa e encontram-se em sintonia com a necessidade de preservação do ambiente no âmbito do próprio parlamento, eis que a soberania popular direcionou seus interesses para tal finalidade.

Com isso, resta claro que a posição de Jeremy Waldron destina-se a dar ou a retomar a legitimidade da política para que ela exerça com qualidade e eficiência a proteção social de direitos.

the issues of policy, principles, justice and rights on which we expect a legislature to deliberate upon" (WALDRON, 1999 , p. 89, 93). 
A lei, política e juridicamente falando, contempla as garantias fundamentais que serão preservadas, nela e por ela.

\section{CONSIDERAÇÕES FINAIS}

Porquanto fundamental à própria vida dos seres, o Meio Ambiente deve ser protegido, em prol da preservação desses espaços para as presentes e futuras gerações. Antes tratado como um mero objeto mercantil, sem qualquer tipo de proteção que não a comercial, o meio ambiente passou gradualmente a ser protegido por leis pontuais entre o período colonial até meados de 1960. Contudo, a partir da conferencia de Estocolmo, em 1972, marco que foi na tutela do ambiente, espraiaram-se diplomas legislativos em prol do ambiente como direito que passou a ser consagrado inclusive em âmbito constitucional.

Com a mudança do paradigma proporcionado pelo documento produzido na Suécia, em 1972, proliferaram, no caso brasileiro, legislações que imprimiram caráter dignificante ao meio ambiente, caso da Lei de Política Nacional do Meio Ambiente. Esta, em seu texto, introduziu a definição de meio ambiente, erigindo-o, sobretudo, à condição de patrimônio publico de proteção coletiva. Porém, em âmbito nacional, foi com a Constituição de 1988 que o Meio Ambiente passou a ser considerado bem fundamental de terceira geração, um direito difuso, coletivo e intergeracional, o que foi corroborado pela jurisprudência do Supremo Tribunal Federal.

Todavia, como destacou o próprio Papa Francisco, a questão ambiental extrapola fronteiras, superando os limites locais, posto que referente à própria vida. Trata-se da morada dos seres, não só no seu espectro natural, mas como ambiente em seu contexto amplo, o que exige compromissos de tutela não só de tal ou qual Estado, mas de todos eles e dos seres que habitam o planeta.

Todavia, no âmbito dos Estados verificam-se, por vezes, conflitos na proteção ambiental. Em razão de eventual desarmonia governamental, a política e o judiciário apresentam dissonância quanto à sua representatividade e os limites de atuação. No Brasil, as causas fundantes desse conflito são apresentadas de formas diversas.

A redemocratização, a intensa atividade jurisdicional, o constitucionalismo abrangente e a falta de representatividade política são causas para o desentendimento e aumento do papel do Judiciário na efetivação dos direitos fundamentais. Contudo, extrai-se da teoria de Dworkin que essa preponderância do magistrado é legítima e correta, uma vez que o juiz é possuidor de mecanismos de garantia da integridade do direito, em prol das maiorias e minorias.

O método indicado pelo jusfilósofo é do idealizado juiz que deve ser referência para todos os outros magistrados em suas atividades como julgadores, os quais, agindo tal como o juiz ideologizado, promoverão a integridade do direito, buscando interpretá-lo à luz dos princípios e da moral, garantindo aos jurisdicionados a efetiva proteção ambiental. No caso do trabalho que ora se conclui, os exemplos foram buscados na atuação proativa do Supremo Tribunal Federal quanto aos questionamentos de inconstitucionalidade da prática da Vaquejada e quanto às disposições do novo Código Florestal.

De outro lado, Jeremy Waldron, ao tecer seus comentários à proposta dworkiana, critica a postura proativa do magistrado e busca outro fundamento para a proteção dos direitos fundamentais, dentre os quais o meio ambiente. Waldron encontra na política o real personagem garantidor dos direitos constitucionais e, para isso, remonta a autores como Hart e Maquiavel.

Em defesa de sua tese, Waldron sustenta que a discussão que antecede a sanção legislativa promove espaço democrático legítimo que, mesmo diante de discordância razoável, acaba por 
encontrar o equilíbrio em prol dos anseios sociais, sem que haja empobrecimento dos discursos majoritários e minoritários.

Assim, considera-se que ambas as possibilidades de proteção ambiental jurídica e política são válidas na prática e no direito brasileiro. Dessa forma, o meio ambiente, enquanto direito fundamental, encontra abrigo nos discursos jurídicos e políticos, que encontram lastro filosófico nas doutrinas de Dworkin e Waldron, respectivamente.

Todavia, não é dado ignorar que a atividade judiciária é supletiva de uma inércia ou de uma não razoável ação do Legislativo. Ignorar tal premissa e legitimar o judiciário para a confecção de políticas públicas significaria referendar uma intromissão indevida de um Poder na seara de atuação de outro Poder estatal.

O texto objetiva assentar a legitimidade de atuação dos Poderes em prol da tutela do meio ambiente, por se tratar, afinal, de direito difuso e fundamental à própria vida dos seres. O legado das linhas acima externadas é, portanto, o de harmonizar a doutrina de Dworkin e Waldron de molde a proporcionar legitimidade de ação adequada e nos limites constitucionais, aos poderes legislativo e judiciário, posto que consagrados, em prol do ambiente, a tutela legal e jurisdicional.

\section{REFERÊNCIAS}

BARROSO, Luis Roberto. Judicialização, ativismo judicial e legitimidade democrática. (Syn)Thesis . Rio de Janeiro, v. 5, p. 23-32, 2012.

BARROSO, Luis Roberto. Neoconstitucionalismo e constitucionalização do Direito (O triunfo tardio do direito constitucional no Brasil). Revista de Direito Administrativo, Rio de Janeiro, v. 240, p. 1-42, abr. 2005. ISSN 2238-5177. Disponível em:

<http://bibliotecadigital.fgv.br/ojs/index.php/rda/article/view/43618/44695>. Acesso em: 1 dez. 2017. doi:http://dx.doi.org/10.12660/rda.v240.2005.43618.

BOBBIO, Norberto. A era dos direitos. Rio de Janeiro: Campus Elsevier. 2004.

BRASIL. Constituição (1988). Constituição da República Federativa do Brasil. Brasília: Senado Federal, Centro Gráfico, 1988.

BRASIL. Lei n. 6.938, de 31 de agosto de 1981. Dispõe sobre a Política Nacional do Meio Ambiente, seus fins e mecanismos de formulação e aplicação, e dá outras providências.

Disponivel em: <http://www.planalto.gov.br/ccivil_03/leis/16938.htm>. Acesso em: 18 nov 2017.

BRASIL. Lei n ${ }^{\circ}$ 8.078, de 11 de setembro de 1990. Dispõe sobre a proteção do consumidor e dá outras providências. Disponível em: < http://www.planalto.gov.br/ccivil_03/leis/L8078.htm>.

Acesso em: 18 nov. 2017.

BRASIL. Supremo Tribunal Federal. Medida Cautelar em Ação Direta de Inconstitucionalidade 3540-DF. Autor: Procurador-Geral da República. Requerido: Presidente da República. Ministro relator: Celso de Mello. Julgamento: 1 set. 2005. Disponível em:

<https://jurisprudencia.s3.amazonaws.com/STF/IT/ADI-MC_3540_DF01.09.2005.pdf?Signature=fG4Szyz240t5t84dyw0u6eGsB7k\%3D\&Expires $=1513775958 \& \mathrm{AW}$ 
SAccessKeyId=AKIAIPM2XEMZACAXCMBA\&response-content-type=application/pdf\&xamz-meta-md5-hash=d7c1883198efe517d455efbeeea468ae> Acesso em: 12 dez. 2017.

CAMPBELL, Tom. Prescriptive legal positivism: law, rights and democracy. London: UCL Press, 2004.

CONSANI, Cristina. F.. O positivismo jurídico normativo na perspectiva de Jeremy Waldron. Quaestio Iuris, v. 8, p. 2424-2448, 2015.

COSTA, Beatriz Souza. A Construção do sujeito constitucional ambiental. Veredas do Direito, Belo Horizonte, v. 8, n. 15, dez. 2011. ISSN 21798699. Disponível em: <http://www.domhelder.edu.br/revista/index.php/veredas/article/view/163/165>. Acesso em: 20 nov. 2017.

CUSTÓDIO, Maraluce Maria; VIEIRA, E. G.. O Desenvolvimento Sustentável À Luz Do Direito Fundamental Ao Meio Ambiente Ecologicamente Equilibrado. Sapientia Revista De Direito Do Centro Universitário Estácio De Belo Horizonte, Belo Horizonte, v. 3, p. 41-64, 2015.

DWORKIN, Ronald. Levando os direitos a Sério. 3 ed. São Paulo: Martins Fontes, 2010.

FRANCISCO. Laudato si: sobre o cuidado da casa comum. São Paulo: Paulus/Loyola, 2015.

MACHADO, Igor Suzano. Comunidade de princípios e princípio responsabilidade: o juiz Hércules confuso diante de uma natureza ameaçada. Revista Veredas do Direito, Belo Horizonte, v. 13, n. 27, p. 243-265, set./ dez. 2016. Disponível em: <http://www.domhelder.edu.br/revista/index. php/veredas/article/view/860>. Acesso em: 28 set. 2017.

MACHADO, Paulo Affonso Leme. Direito ambiental brasileiro. 23. ed. São Paulo: Malheiros Editores, 2015.

MAQUIAVEL, Nicolau, Discourses on livy. Harvey C. Mansfield e Nathan Tarcov (trad.), Chicago, University of Chicago Press, 1996.

MARMELSTEIN, George. Curso de direitos fundamentais. São Paulo: Editora Atlas, 2008.

RIBEIRO, Leonardo Ferres da Silva. Princípio da inafastibilidade do controle jurisdicional. In: Olavo de Oliveira Beto; Maria Elizabeth de Castro Lopes. (Org.). Princípios processuais civis na Constituição Federal. Rio de Janeiro: Elseier, 2008, v. 1, p. 47-77.

SAMPAIO, José Adércio Leite. Direitos fundamentais: retórica e historicidade. 2 ed. Belo Horizonte: Del Rey, 2010.

WALDRON, Jeremy. A dignidade da legislação. Tradução de Luís Carlos Borges. São Paulo: Martins Fontes, 2003.

WALDRON, Jeremy.Law and disagreement. New York: Oxford University, 1999. 